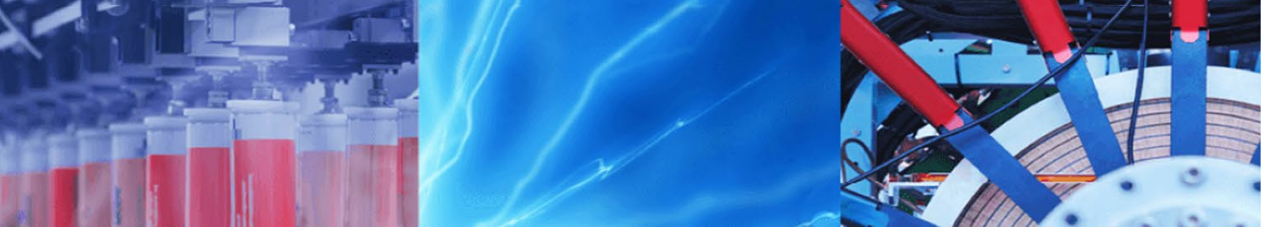

Research Article

\title{
An investigation on the suitability of modern nondestructive testing methods for the inspection of specimens manufactured by laser powder bed fusion
}

\author{
Cara G. Kolb ${ }^{1}$ (1) $\cdot$ Katja Zier ${ }^{2}$. Jan-Carl Grager ${ }^{2} \cdot$ Andreas Bachmann $^{1} \cdot$ Tobias Neuwirth $^{3} \cdot$ Simon Schmid $^{2}$. \\ Maria Haag ${ }^{4} \cdot$ Markus Axtner $^{4} \cdot$ Fabian Bayerlein $^{1} \cdot$ Christian U. Grosse ${ }^{2} \cdot$ Michael F. Zaeh $^{1}$
}

Received: 5 January 2021 / Accepted: 3 June 2021

Published online: 29 June 2021

(C) The Author(s) 2021 OPEN

\begin{abstract}
Laser powder bed fusion (L-PBF) is increasingly used to fabricate functional parts used in safety-relevant applications. To ensure that the sophisticated part specifications are achieved, $100 \%$ quality inspections are performed subsequent to the buildup process. However, knowledge about the detectability of defects in L-PBF parts using NDT methods is limited. This paper analyzes the suitability of NDT techniques in an ex situ environment, in particular active infrared thermography, neutron grating interferometry $(\mathrm{nGl}), X$-ray computed tomography, and ultrasonic testing for the examination of L-PBF parts made from Inconel 718. Based on a test specimen with artificially inserted defects with varying dimensions and depths, these NDT techniques were compared in terms of their attainable resolution and thus defect detection capability. The empirical studies revealed that $\mathrm{nGl}$ shows the highest resolution capability. It was possible to detect defects with a diameter of 100-200 $\mathrm{m}$ at a depth of $60-80 \mu \mathrm{m}$. The results are discussed with regard to their relevance for the examination of L-PBF parts and thus not only contribute to a better understanding of the potential of the NDT techniques in comparison but also assist stakeholders in additive manufacturing in evaluating the suitability of the NDT techniques investigated.
\end{abstract}

Keywords Laser powder bed fusion (L-PBF) · Defect detection · Active infrared thermography imaging (aIRT) - Neutron grating interferometry $(\mathrm{nGl}) \cdot$ Computed tomography $(\mathrm{CT}) \cdot$ Ultrasonic testing (UT)

\section{Introduction}

Laser powder bed fusion (L-PBF) is a suitable additive manufacturing (AM) technology for the processing of weldable metals and alloys. These include mainly steel and iron-based alloys, aluminum and its alloys, titanium and its alloys, and nickel-based alloys, such as Inconel [1]. Recent progress in novel optics and laser systems has opened up possibilities to process further metal materials, such as copper and tungsten [1]. In L-PBF, powdered raw material is applied in layers and selectively melted by a focused laser beam. Melting and resolidification lead to cooling rates in the order of $10^{6} \mathrm{~K} / \mathrm{s}[2,3]$. This concentrated heat input causes residual stresses and warpage, which in turn can result in the formation of defects [4]. Furthermore, the L-PBF process is subject to more than 100 influencing

$\triangle$ Cara G. Kolb, cara.kolb@iwb.tum.de|'Department of Mechanical Engineering, Institute for Machine Tools and Industrial Management, Technical University of Munich, Boltzmannstr. 15, 85748 Garching, Germany. ${ }^{2}$ Chair of Non-destructive Testing, Technical University of Munich, Franz-Langinger-Straße 10, 81245 Munich, Germany. ${ }^{3}$ Research Neutron Source Heinz Maier-Leibnitz (FRM II), Technical University of Munich, Lichtenbergstr. 1, 85748 Garching, Germany. ${ }^{4}$ FIT Additive Manufacturing Group, Am Grohberg 1, 92331 Lupburg, Germany.

SN Applied Sciences ～～～（2021) 3:713 $\quad$ https://doi.org/10.1007/s42452-021-04685-3 
variables [5]. Process instabilities caused by an unfavorable interaction of the process parameters can also lead to the formation of defects. Typical defects that occur in the L-PBF process are the following [6, 7]:

Poor consolidation and wetting are caused by a varying energy input or wetting properties. It can lead to, e.g., gas pores and lack of fusion pores, which are commonly filled with powder [8].

Delamination refers to partial or complete detachments of individual layer or layer composites. They are mainly caused by residual stresses and insufficient bonding [9, 10]. According to Ladewig et al. [11], delaminations usually show an extension of 100 to $300 \mu \mathrm{m}$ in the level of the individual layers.

Cracks comprise hot cracks and stress cracks, which occur when the strength limits are exceeded due to high-temperature gradients and cooling rates during the buildup process $[12,13]$. Carter et al. [13] investigated the formation of hot cracks in L-PBF parts made from a nickelbased alloy. The hot cracks mainly developed along the build direction, which also represents the main extension direction of the cracks. The cracks mainly occur along the grain boundaries. Since the microstructure consists of columnar grains along the build direction, the cracks are therefore predominantly located along this direction and thus across the grains. The length of the hot cracks ranged in Carter et al. [13] from less than $100 \mu \mathrm{m}$ up to a few $100 \mu \mathrm{m}$.

Parts with an intolerable number of defects must be reliably identified and subsequently removed from production. To the best knowledge of the authors, only a few studies have been published that investigate the suitability of common nondestructive testing (NDT) methods for the inspection of L-PBF components. However, no comparative study has yet been performed with the NDT methods investigated in this paper on an identical test specimen. In the following, the research activities in the field of NDT of L-PBF components as well as relevant studies on conventionally produced metal components are summarized. In particular, the NDT methods used in this study, which are active infrared thermography (aIRT), X-ray computed tomography (CT), neutron grating interferometry $(\mathrm{nGl})$, and ultrasonic testing (UT), are addressed. All of these methods are suitable for the inspection of metals and alloys suitable for welding and thus also for the metal investigated in this study, which is Inconel 718.

Active infrared thermography (aIRT) Kolb et al. [14] investigated the suitability of aIRT in an ex situ arrangement for L-PBF parts manufactured from the nickel-based alloy 718 . The experimental study was thus performed outside an L-PBF machine subsequent to the building process. This examination served as a preliminary study to enable an in situ layerwise monitoring system. Other researchers investigated the suitability of alRT for ex situ inspection purposes of conventionally fabricated metal parts made of Inconel 718 and a further nickel-based alloy [15, 16].

Different assertions can be found in the literature regarding the relationship between the diameter and the depth of the minimum detectable defect using alRT. The publications refer to metal parts, for which the detection of defects is even more challenging. Compared to polymers, for example, metals have a much higher thermal conductivity. This leads to a lower achievable diameter-todepth ratio of defects to be detected. According to Shepard et al. [17], the detectable diameter-to-depth ratio of defects is limited by the thermal diffusion process inside the material to a minimum value of 1 . Merkle et al. [18] verified this statement by conducting various test runs with various materials, such as aluminum, ceramics, and lexan. Maldague et al. [19] reported similar threshold values and stated that this is a valid assumption for homogeneous isotropic materials [20]. It can be assumed that the detection of flaws with a diameter-to-depth ratio of less than 1 is theoretically possible, but practically not achievable in all test situations, especially with highly conductive materials.

$X$-ray computed tomography (CT) X-ray computed tomography is a well-established method for NDT of additively manufactured parts. In addition to the detection of defects, X-ray CT is used for meteorology purposes. A review of the applications for $\mathrm{X}$-ray $\mathrm{CT}$ in additive manufacturing is given in Du Plessis et al. [21]. Lopez et al. [22] discovered that defects as small as $3 \mu \mathrm{m}$ were recognizable in small L-PBF parts made from AlSi10Mg, Inconel 718, and Ti6AI4V with a square base size of $3-6 \mathrm{~mm}^{2}$. The $X$-ray computed tomography (CT) system used had a minimum spot size of $\leq 6 \mu \mathrm{m}$. Tammas-Williams et al. [23] conducted experiments with parts made from the titanium alloy Ti6Al4V, which were fabricated by electron beam melting (EBM). The smallest pores detected by the $\mathrm{CT}$ had a diameter of approximately $5 \mu \mathrm{m}$.

Neutron radiation Brooks et al. [24] used a combination of a high-resolution neutron tomography system and a grating-based interferometer $(\mathrm{nGl})$ in order to investigate the porosity of titanium cubes with an edge length of $1.5 \mathrm{~cm}$ manufactured by EBM. With this test setup, sub-pixel scattering phenomena could be observed, and thus, various pore structures could be identified. However, destructive metallographic tests for validation purposes were not conducted. Michaeloudaki et al. [25] used neutron tomography in order to evaluate the quality of adhesive joints in aluminum. The experiments showed a high conformity of the values for the artificially induced and the measured defective areas, although the detectability depended on the capability to differentiate between different gray levels in the obtained images. In Griesche et al. [26], neutron 
tomography was used to explore hydrogen embrittlement and blistering in technical iron. A spatial resolution of $25 \mu \mathrm{m}$ was achieved with the setup.

Ultrasonic testing (UT) Everton et al. [27] studied the suitability of laser-generated surface waves for the detection of the artificial defects in L-PBF parts made from the titanium alloy Ti6Al4V. The experiments were performed in a test facility for laser ultrasonic testing (LUT), where they could be controlled remotely. With the profile images (B-scans), the minimum detectable diameter was $0.725 \mathrm{~mm}$ for defects at a depth up to $0.7 \mathrm{~mm}$. Further studies have been conducted applying ultrasonic testing (UT) for in situ monitoring [28-33].

The studies described, however, are limited to investigations using only one NDT technique, although in practice it is often advantageous to use different methods. Since, to the best of the authors' knowledge, no studies thus far have provided a comparison of the suitability of the aforementioned NDT methods for detecting defects in metal parts manufactured by L-PBF, this paper evaluates this. A similar study to the one presented in this paper, but concerned with different volumetric NDT techniques, is given in Obaton et al. [34]. Both studies are expected to complement each other well.

In general, NDT methods are compared by first defining the critical defects to be detected (type, dimensions, position) (Effect of Defect) and then determining their Probability of Detection (PoD). Since this manuscript allows, for the first time, a comparison of the NDT methods described previously for an L-PBF part, this publication is to be regarded as a preliminary work for further studies and thus a simplified approach was taken.

Therefore, the approach pursued in this paper is as follows. The attainable resolution and defect detection capability of the respective NDT techniques are investigated using a test specimen with artificially inserted defects of varying dimensions and depths. The NDT methods are compared on the basis of their minimum detectable defect size. The diameter-to-depth ratio, which is a common parameter in alRT, is not suitable due to widely varied operating principles of the respective NDT techniques. In aIRT, the detectability is predominantly limited by the contrast of the transient temperature of the sample surface between defective and non-defective areas. The contrast, in turn, primarily depends on the diameter-to-depth ratio. Detectability in X-ray CT and nGl is, however, mainly limited by the thickness of the material. Above a certain thickness, $X$-rays and neutrons can no longer pass through the material. In UT, the detectability depends on the location of the defect in the component. This is due to the scattering and attenuation of the elastic waves.

Based on the results, process-specific potentials and constraints were analyzed to support the selection of appropriate methods, depending on the required detection accuracy of the defects of interest.

\section{Materials and methods}

\subsection{Test specimen}

The experimental investigations were performed using the same test specimen (see Fig. 1) to ensure that the defects measured would be reproducible for all investigated NDT methods and thus the results comparable.

A rectangular cuboid with an edge length of $50 \mathrm{~mm}$ and a height of $25 \mathrm{~mm}$ served as a test specimen. An arrangement of cylindrically shaped defects was provided in the underlying computer-aided design model. The artificial defects exhibit internal blind holes with almost the same depth, but with varying diameters. These blind holes are located at different distances from the surface and thus have different depths relative to the surface. The blind holes represent artificial features with a limited transferability to process-related defects, such as pores or delaminations. Nevertheless, this study allows sensitivity to be examined to a certain defect size. In addition, the results can provide indications of the feasibility of producing internal geometries of a particular extension and depth, as required for, e.g., cooling channels.

In order to facilitate the subsequent evaluation process, a scale was included on the surface of the test specimen. The $x$-y-plane represented the plane of a layer in the L-PBF process. The building direction was along the z-axis. In order to facilitate the understanding of the position and orientation of the test specimen in relation to the defect arrangement, the coordinate system introduced was applied for the respective test setups and the corresponding evaluation. The diameter and the depth, defined as the distance to the surface of the cuboid, of the cylindrical voids were systematically varied and arranged in a matrix configuration within the sample.

The hole diameter was gradually set between $20 \mu$ m and $2000 \mu \mathrm{m}$, and the depth of the defects ranged between $20 \mu \mathrm{m}$ and $80 \mu \mathrm{m}$, with the minimum depth corresponding to the thickness of a single powder layer of the L-PBF process:

- Diameter $20 \mu \mathrm{m}, 40 \mu \mathrm{m}, 60 \mu \mathrm{m}, 80 \mu \mathrm{m}, 100 \mu \mathrm{m}, 200 \mu \mathrm{m}$, $300 \mu \mathrm{m}, 500 \mu \mathrm{m}, 1000 \mu \mathrm{m}, 2000 \mu \mathrm{m}$

- Depth $20 \mu \mathrm{m}, 40 \mu \mathrm{m}, 60 \mu \mathrm{m}, 80 \mu \mathrm{m}$

Additionally, droplet-shaped defects were included in the lower part of the test specimen. Although the latter features actually serve an experimental study that is not dealt with in this manuscript, they are visible in some 
Fig. 1 Schematic overview of the test specimen containing artificial blind holes with relevant sectional views according to DIN ISO 128-40 [35], specifications of the respective defects in matrix representation $(a / b)$ with variables a diameter of the defect in $\mu \mathrm{m}$ and $\mathbf{b}$ depth of the defect in $\mu \mathrm{m}$. (Droplet-like defects are not depicted.)
Table 1 Parameter settings for the fabrication of the test specimen

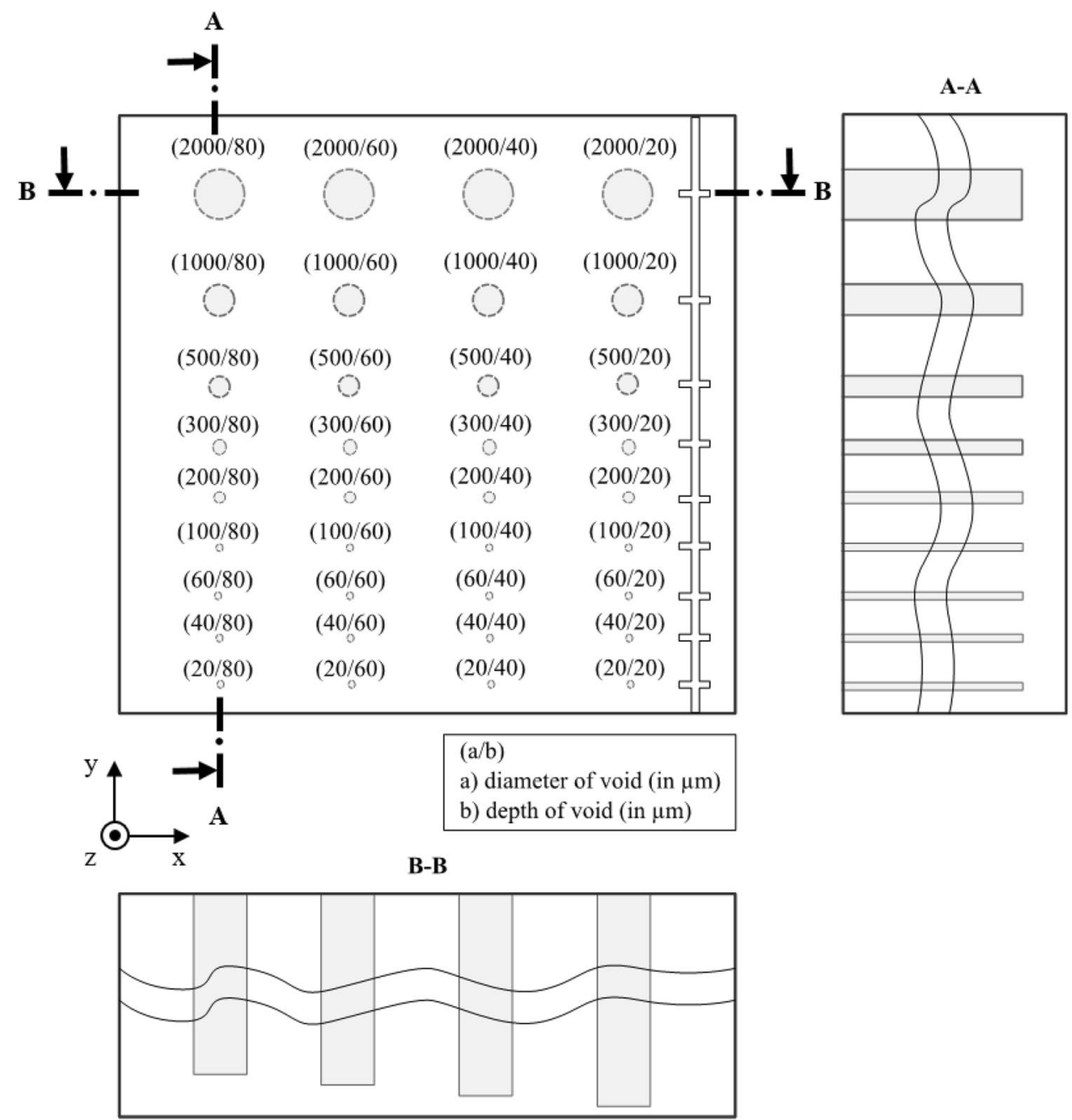

\begin{tabular}{ll}
\hline Parameter & Value \\
\hline Laser power $P$ & $195 \mathrm{~W}$ \\
Scan velocity $v$ & $1200 \mathrm{~mm} / \mathrm{s}$ \\
Hatch distance $h$ & $90 \mathrm{~mm}$ \\
Layer thickness $s$ & $20 \mathrm{~mm}$ \\
\hline
\end{tabular}

\subsubsection{Active infrared thermography (aIRT)}

Active infrared thermography (aIRT) relies on the use of thermal excitation sources to generate a thermal contrast between defects located inside the test specimen and the intact matrix. Typical heat sources are light, ultrasound, or eddy currents [36]. In addition to optical excitation sources, such as those presented by Kolb et al. [14], other modalities like hot air can also be applied [37]. The thermal wave introduced propagates through the test specimen. Depending on the heat diffusion rate of the investigated matrix and occurring defects, the transient temperature of the sample surface gives an indication of the geometrical extension of the defects. Therefore, an infrared camera is usually employed to evaluate the development of the surface temperature over time.

In this paper, the artificially produced channel-like defects were investigated. A heat stream was directed into the channels through the activation of a conventional laboratory heat gun for $30 \mathrm{~s}$ (see Fig. 2), heating up the material from the inside. Directly after the hot air flow was temperature of approx. $20^{\circ} \mathrm{C}$ 


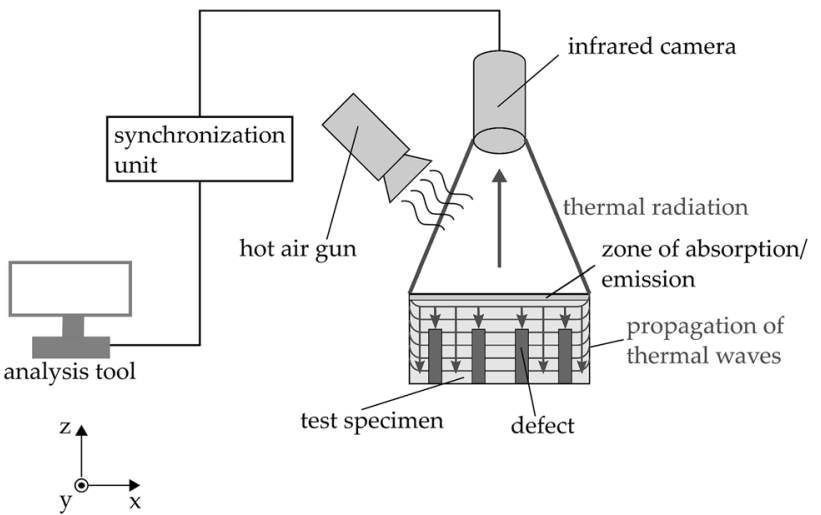

Fig. 2 Schematic illustration of a typical reflection test setup for the defect detection by means of active thermography with hot air as excitation source

Table 2 Technical specifications of the used infrared camera setup with the additional close-up lens

\begin{tabular}{ll}
\hline Parameter & Value \\
\hline Sensitivity $T_{\text {sens }}$ & $<30 \mathrm{mK}$ \\
Image resolution & $640 \times 480$ \\
Pixel pitch $p$ & $50 \mu \mathrm{m}$ \\
Image frequency $f$ & $30 \mathrm{~Hz}$ \\
\hline
\end{tabular}

stopped, the sample surface was analyzed in a reflection configuration using the infrared camera (SC 660, FLIR Systems Inc., USA) (see Table 2). It was set up with a $24^{\circ}$ optical lens and an additional close-up lens $(2.9 \times, 50 \mu \mathrm{m})$. In a second configuration, heat was applied to the surface with the closed channels. The optical beam path of the camera was set up in both cases in the direction of the channels. Due to the discrepancy of time-dependent thermal wave propagation through the artificial channels compared to the metal matrix, defects caused detectable hot spots at the inspection surface.

\subsubsection{X-ray computed tomography (CT)}

An X-ray computed tomography (CT) system uses electrically generated $\mathrm{X}$-rays, which are capable of penetrating the test specimen from different angles along a rotation axis (see Fig. 3). As X-rays pass through matter, they are attenuated due to different absorption and scattering effects, leading to a decrease in the initial intensity of the $\mathrm{X}$-ray beam. The attenuation of X-rays is dependent on the density and the atomic number of the material. The amount of radiation reaching the array detector is registered, and two-dimensional X-ray projections of the object are generated. The pixels contained in such an image are represented in terms of the relative radiodensity corresponding to a grayscale. For a typical examination of a test specimen, a series of projections around $3360^{\circ}$ rotation of

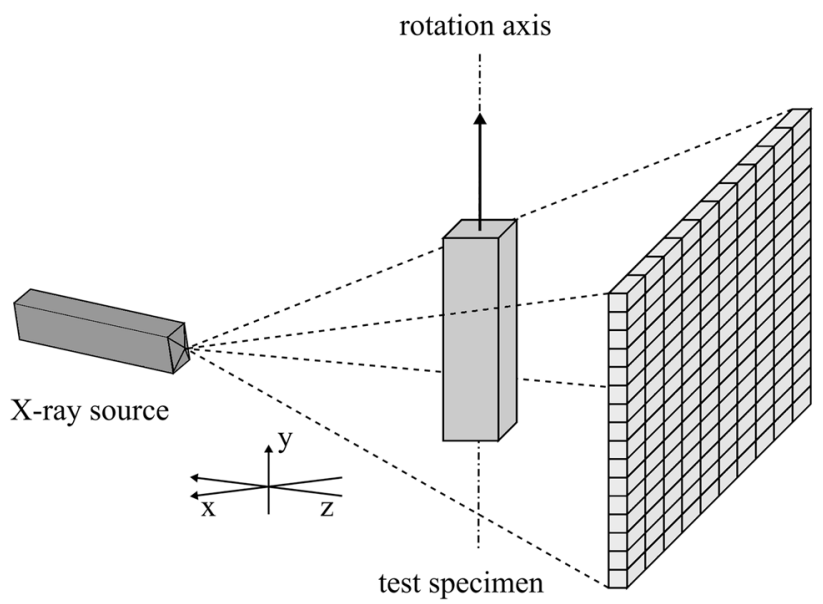

array detector

Fig. 3 Schematic illustration of a typical test setup for the defect detection by means of an X-ray CT

Table 3 Parameter settings used for X-ray imaging

\begin{tabular}{ll}
\hline Parameter & Value \\
\hline Tube voltage $U$ & $240 \mathrm{kV}$ \\
Tube current $I$ & $130 \mu \mathrm{A}$ \\
Number of projections $N$ & 1800 \\
\hline
\end{tabular}

the object is acquired. A digital three-dimensional volume object is then reconstructed from this raw data, which is composed of small volume elements. These so-called voxels correspond to three-dimensional pixels. After a subsequent segmentation, a digital volume object, comparable to a CAD model, is obtained enabling a qualitative and quantitative analysis of all surfaces and the inside of the test specimen including defects.

The X-ray CT system (D2, Diondo, Germany) used for the experiments was equipped with a $300 \mathrm{kV}$ open microfocus $X$-ray vacuum tube and a $3000 \times 3000$ pixel flat panel detector. The parameter settings used for the $X$-ray imaging of the test specimen are given in Table 3. The software provided by Diondo was used for the reconstruction, using the analytical reconstruction with the Feldkamp-Davis-Kress algorithm, of the test specimen and the evaluation of the cross-sectional images. The voxel size of the reconstructed volume was $43.7 \mu \mathrm{m}$.

\subsubsection{Neutron grating interferometry}

Neutron grating interferometry $(\mathrm{nGl})$ is a specialized form of neutron imaging, which makes it possible to simultaneously obtain information about the attenuation, phase shift, and ultra-small-angle scattering of neutrons in material structures in the micrometer range. In Fig. 4, a sketch 


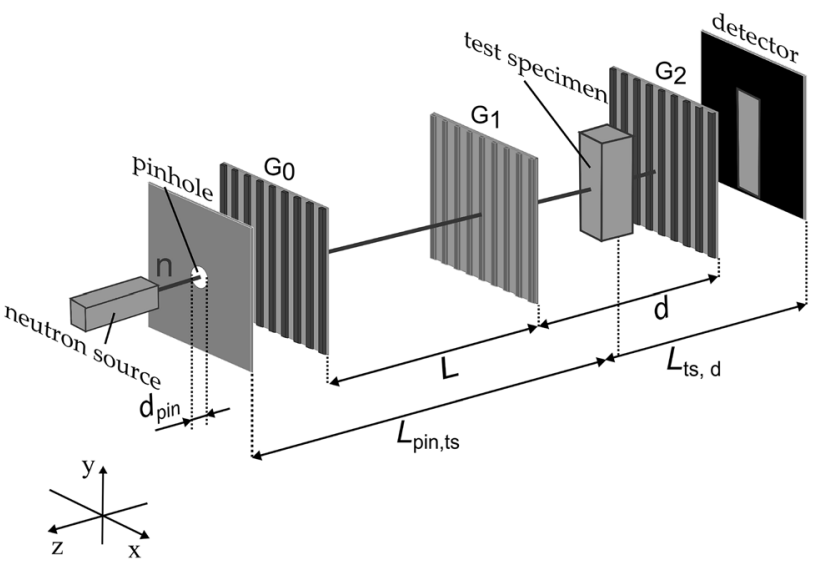

Fig. 4 Schematic illustration of the neutron grating interferometry with the pinhole, the source grating $\mathrm{G} 0$, the phase grating $\mathrm{G} 1$, the analyzer grating $\mathrm{G} 2$ and the detector. The test specimen was positioned between $\mathrm{G} 0$ and $\mathrm{G} 1$

of an $\mathrm{nGl}$ setup in Talbot-Lau geometry is presented. An $\mathrm{nGl}$ setup consists of three line gratings, one phase grating $\mathrm{G1}$, and two absorption gratings $\mathrm{G} 0$ and $\mathrm{G} 2[38,39]$, placed inside an imaging beamline. $G 0$ divides the neutron beam into an array of coherent line sources, which are mutually incoherent. Downstream, the structuring of $\mathrm{G} 1$ causes a periodic phase modulation to be imprinted on the neutron wavefront. This phase modulation causes a complex intensity and phase modulation to appear downstream of G1, called the Talbot carpet. At odd fractional Talbot distances, the intensity modulation reaches its maximum. To analyze this intensity modulation, grating $\mathrm{G} 2$ is placed at an odd fractional Talbot distance. For an $\mathrm{nGl}$ measurement, one of the gratings has to be moved perpendicular to the grating lines, resulting in an intensity modulation in each detector pixel. The sample changes this intensity modulation, due to attenuation, refraction, and scattering. Through analysis of the intensity modulation and comparison with an $\mathrm{nGl}$ measurement without a sample, information about the transmission (TI) and the scattering (DFI) can be recovered [40]. The achievable spatial resolution, resulting from the effective pixel size $(27 \mu \mathrm{m} \times 27 \mu \mathrm{m})$, the scintillator thickness $(100 \mu \mathrm{m})$, and the geometric resolution amounted to 50 to $60 \mu \mathrm{m}$. The geometric resolution is defined by the pinhole diameter $d_{\text {pin }}$ the distance $L_{\text {pin,ts }}$, and the distance $L_{t s, d}$ [41]. In contrast, the structure size discernible by the $\mathrm{nGl}$ is decoupled from the spatial resolution and instead depends on the correlation length of the nGl setup [42, 43]. The correlation length is defined by the neutron wavelength used ( $4 \AA$ ), the distance between the specimen and $\mathrm{G} 2(2 \mathrm{~cm})$, and the periodicity of $\mathrm{G} 2(13.3 \mu \mathrm{m})$ [42]. In the case of this experiment, the value of the correlation length varied, due to the thickness of the specimen, between 0.6 and $1.2 \mu \mathrm{m}$.
Table 4 Geometric characteristics of the used test setup

\begin{tabular}{ll}
\hline Parameter & Value \\
\hline$d_{\text {pin }}$ & $35.6 \mathrm{~mm}$ \\
$L_{\text {pin,ts }}$ & $8.95 \mathrm{~m}$ \\
$L_{\text {tsd }}$ & $3 \mathrm{~cm}$ \\
$L$ & $6.89 \mathrm{~m}$ \\
$d$ & $60.8 \mathrm{~cm}$ \\
\hline
\end{tabular}

The experiments were conducted at the ANTARES instrument operated by the FRM II of the Heinz MaierLeibnitz Zentrum (MLZ) in Garching, Germany $[44,45]$. The geometric characteristics are given in Table 4.

\subsubsection{Ultrasonic testing (UT)}

Full matrix capture (FMC) is an emerging ultrasonic data acquisition technique using elastic waves and phased array transducers [46]. Most of these multi-element probes contain $\mathrm{N}$ linearly arranged rectangular piezoelectric elements with an individual width of only a few tenths of a millimeter. Thus, the transducer elements are often approximated as line sources for cylindrical waves [47]. During the first FMC pulse, element one emits a highly diverging wavefront into the inspection volume, while all elements are set to receive mode. The wavefront is either penetrating the entire volume or is partly reflected at reflectors like defects. This acquisition process is repeated within milliseconds for all $\mathrm{N}$ transducer elements so that a raw data set of $N^{2}$ echo signals from all possible transmitter-receiver pairs is recorded. Then, image reconstruction algorithms, such as the total focusing method (TFM) [46], are usually applied. At the beginning of the 2D TFM, the desired imaging plane is discretized into pixels, serving as focal spots. The entire FMC data set is then focused digitally in every point of the image. Therefore, for each recorded echo signal, an amplitude value is extracted at a defined time $t$. For a given emitter-pixel-receiver combination, $t$ corresponds to a wavefront's time of flight from the transmitter to the focal spot $\left(t_{1}\right)$ and back to the receiver $\left(t_{2}\right)$ (see Fig. 5). A pixel value in the TFM image is then given by the sum of all $N^{2}$ extracted amplitudes. The TFM algorithm provides images with an improved sensitivity to small reflectors, since it is based on coherent superposition of returning echo signals and on incoherent noise cancelation, induced, e.g., by grain boundaries [46].

An ultrasonic acquisition unit (OEM-PA 64/64, Advanced OEM Solutions, USA) and a linear phased array probe from Olympus (see Table 5) were used for the FMC recording. For this purpose, the transducer was placed on top of the cubic test specimen, close to the smallest artificial defects, and oil served as couplant. Due to the limited specimen size, only the first 48 of 64 transducer elements present were used for 


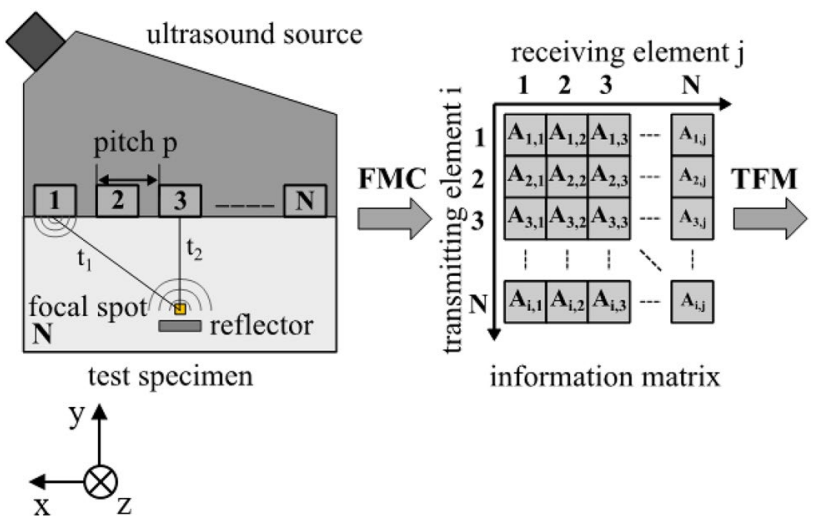

Fig. 5 Schematic illustration of the total focusing method for a single transmitter-pixel-receiver combination [48]

Table 5 Technical specifications of the ultrasonic transducer used (10L64-A2)

\begin{tabular}{ll}
\hline Parameter & Value \\
\hline Nominal frequency $f_{\text {nom }}$ & $10 \mathrm{MHz}$ \\
Number of elements $N$ & 64 (48 were used) \\
Element pitch $p$ & $0.6 \mathrm{~mm}$ \\
Aperture size $d$ & $38.4 \mathrm{~mm}(28.8 \mathrm{~mm}$ were used) \\
\hline
\end{tabular}

the FMC data acquisition (see Fig. 5). The digitalization of the recorded echo signals was performed with 12 bits at a sampling rate of $100 \mathrm{MHz}$. The TFM algorithm was implemented in MATLAB using a pixel size of $0.05 \mathrm{~mm}$. To ensure accurate time-of-flight calculations, the longitudinal speed of sound was experimentally determined to be $5850 \mathrm{~m} / \mathrm{s}$ perpendicular to the scanning surface.

\subsubsection{Metallurgical testing}

Subsequent to the NDT investigations, the test specimen was analyzed by metallography to provide a reference characterization method. The aim was to determine whether the artificial defects were also present in the final component. The bottom side of the test specimen was gradually ground and polished to reveal the channels. Subsequently, the microsections were examined using an optical microscope (MM-40, Nikon, Japan) and a scanning electron microscope (SEM) (Tabletop Microscope TM3030 Plus, Hitachi, Japan).

\section{Results}

\subsection{Active infrared thermography (aIRT)}

Figure 6 shows the sample surface (front view, inset artificial defects) investigated by aIRT as well as the recorded view of the rear (open artificial defects) for comparison. Open defects with an intended diameter of $2000 \mu \mathrm{m}$, $1000 \mu \mathrm{m}, 500 \mu \mathrm{m}$, and $300 \mu \mathrm{m}$ were detected when the additional close-up lens was used. However, due to the high heat diffusion rate of the metal matrix, the detectability of inset artificial defects is limited. An incomplete metal matrix surface layer allows the detection of inset defects with a high diameter-to-depth ratio (minimum of 25), which was already shown by Kolb et al. [14] for pulse thermography experiments. Due to the temperature difference of hot air (inset air channels) and the metal matrix surface layer, a distinct thermal contrast resulted. However, if the diameter-to-depth ratio becomes smaller, the increased density of the high heat diffusion metal cover layer prevents the formation of a thermal contrast for defect detection for the closed artificial defects. Furthermore, the melting tracks resulting from the L-PBF process are clearly visible in the image recorded from the front.

\subsection{X-ray computed tomography (CT)}

The CT images of the test specimen are given in Fig. 7 . Both a top view and sectional views are depicted, whereby the evaluation lines were set in parallel to the printed scale. The images show a low contrast, which is reasoned in, e.g., occurring radiation effects, which were mainly caused by the high density of the material. The radius or diameter, respectively, of the defects of the first three rows with an intended diameter of $2000 \mu \mathrm{m}, 1000 \mu \mathrm{m}$, and $500 \mu \mathrm{m}$ was measurable. The defects with a diameter of $300 \mu \mathrm{m}$ are barely visible due to low contrast. However, it was not possible to determine the entire circumferential surface area precisely, nor thus the diameter along the entire canal. Defects with a diameter of less than $300 \mu \mathrm{m}$ were neither indicated in the images nor measurable. The droplet-shaped defects that are subject to further studies were recognizable in the images.

\subsection{Neutron grating interferometry (nGI)}

The investigations within $\mathrm{nGI}$ demonstrated that the DFI and the $\mathrm{Tl}$ image are suitable for the characterization of the artificial defects. A distinct contrast was obtained for the flaws of the rows with an intended diameter of $2000 \mu \mathrm{m}, 1000 \mu \mathrm{m}, 500 \mu \mathrm{m}, 300 \mu \mathrm{m}$, and $200 \mu \mathrm{m}$ for both 

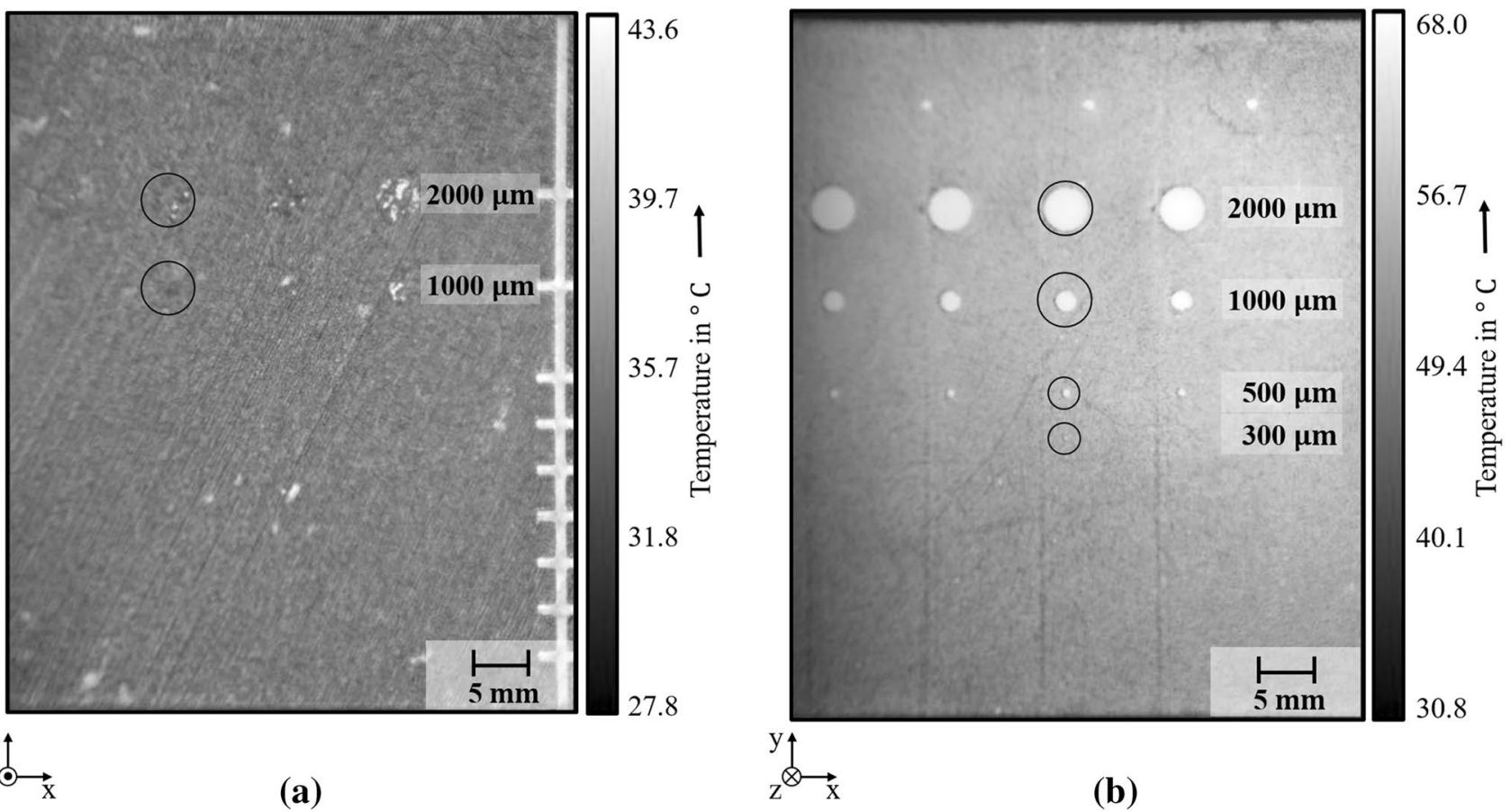

(a)

(b)

Fig. 6 Thermograms of the test specimen with a front view, closed artificial defects, $\mathbf{b}$ rear view, open artificial defects. The black circles illustrate exemplary defects from the back view to the corresponding open artificial defects

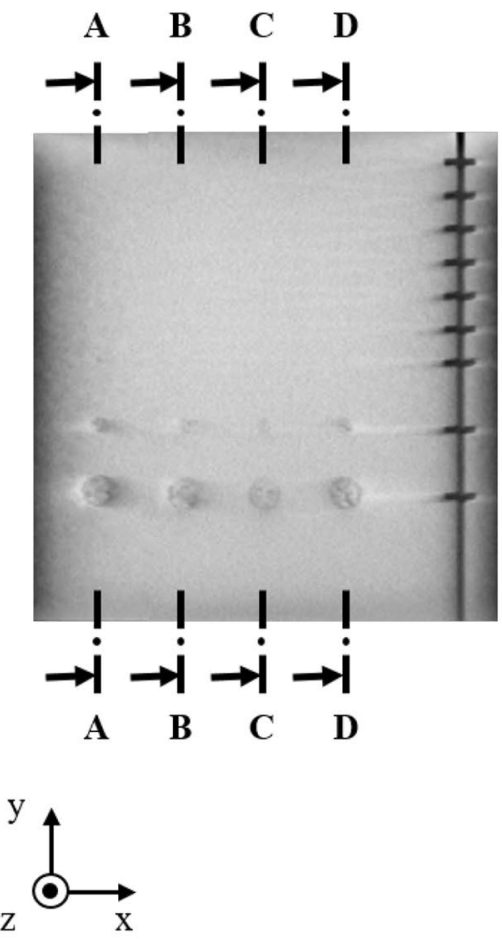

A-A
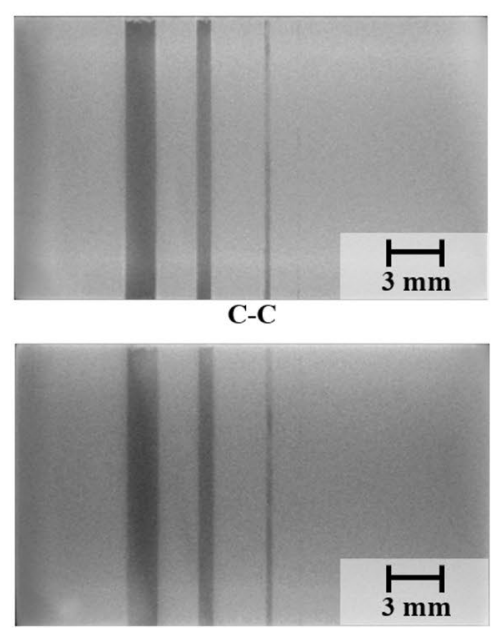

B-B

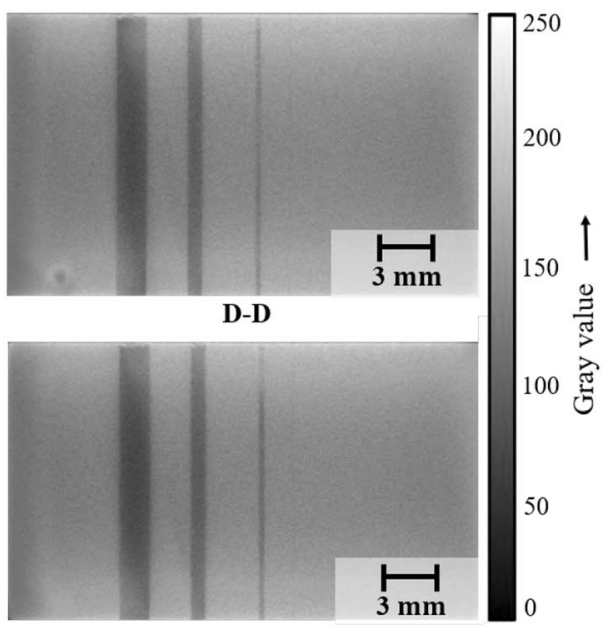

Fig. 7 Reconstructed CT images of the test specimen with a top view and sectional views; the evaluation lines were set in parallel to the printed scale (see also Fig. 1)

\section{SN Applied Sciences}



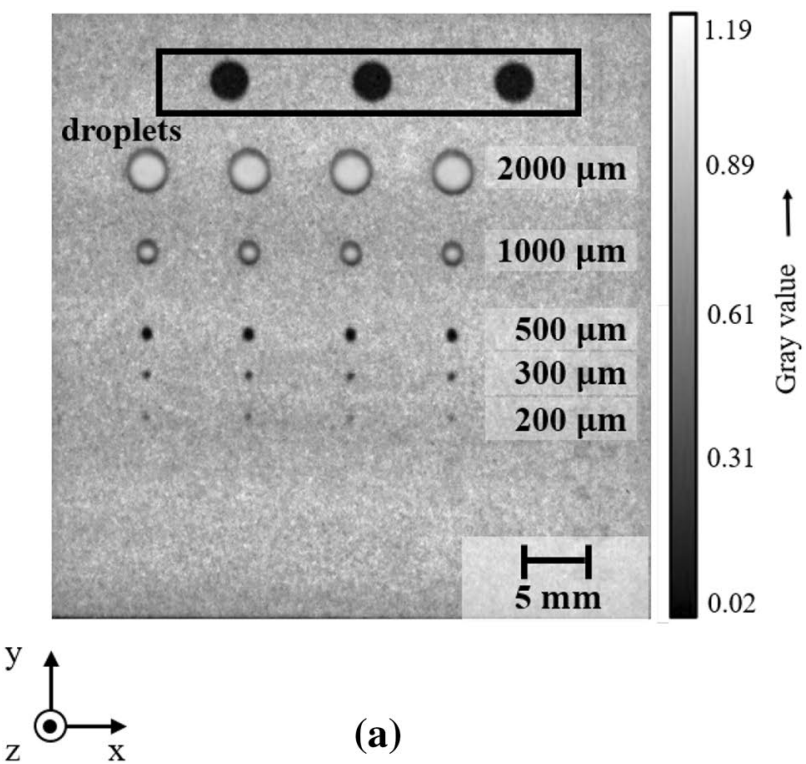

(a)
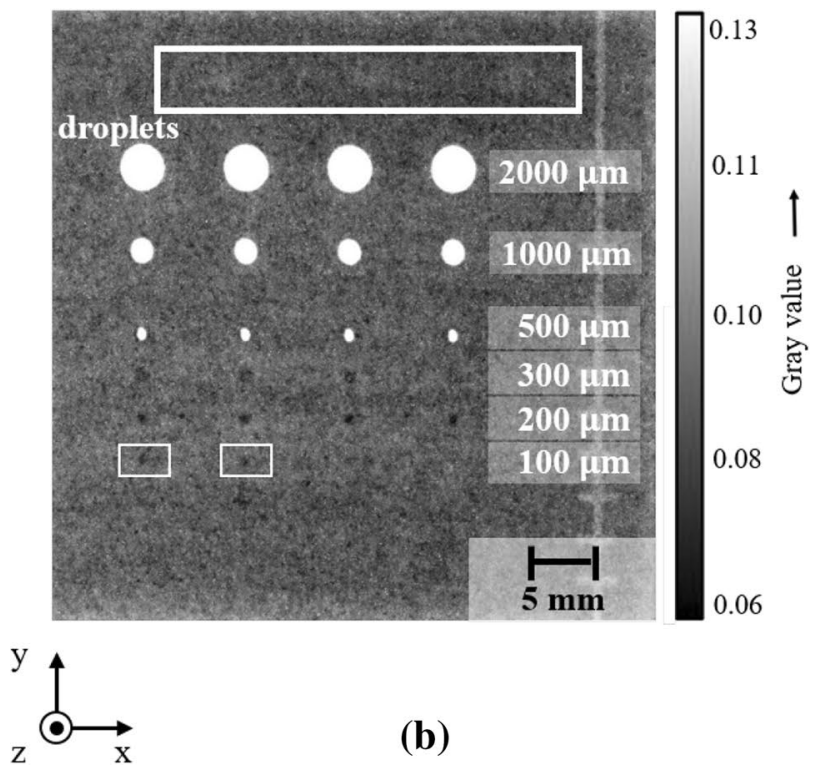

(b)

Fig. 8 Images of the test specimen generated by nGI with a DFI image (range: $0.02-1.19)$ and b TI image (range: 0.06-0.13); the diameters of the recognized defects were added to the recording

image types (see Fig. 8). In the Tl image, a clear contrast is discernible for two defects with an intended diameter of $100 \mu \mathrm{m}$. The droplet-like defects led to a significant contrast in the DFI image, but not in the respective TI image. The TI depends on the thickness, density, and attenuation coefficient of the material in the path of the neutron beam. In contrast, the DFI depends on the thickness, the scattering coefficient, and microstructure of the material. The droplets have a different microstructure than the surroundings. This configuration thus results in no signal difference in the $\mathrm{Tl}$, but causes a signal change in the DFI.

This indicates that the suitability of the respective evaluation methods depends on the depth and dimensions of the defects to be investigated. Consequently, a combination of both image types for analysis purposes may yield more comprehensive results.

\subsection{Ultrasonic testing (UT)}

Figure 9 shows the 2D-TFM reconstruction result of the test specimen. Reflectors with diameters between $300 \mu \mathrm{m}$ and $2000 \mu \mathrm{m}$ could clearly be detected. The latter, however, appear smaller in size in the TFM image and show a lower pixel intensity. This is caused by the probe position on the specimen's surface and the blind hole arrangement, as the smaller superjacent flaws partially shadow the $2000 \mu \mathrm{m}$ reflectors. Regardless of the chosen inspection surface, holes smaller than $300 \mu \mathrm{m}(\sim \lambda / 2)$ could not be detected with the test configuration.

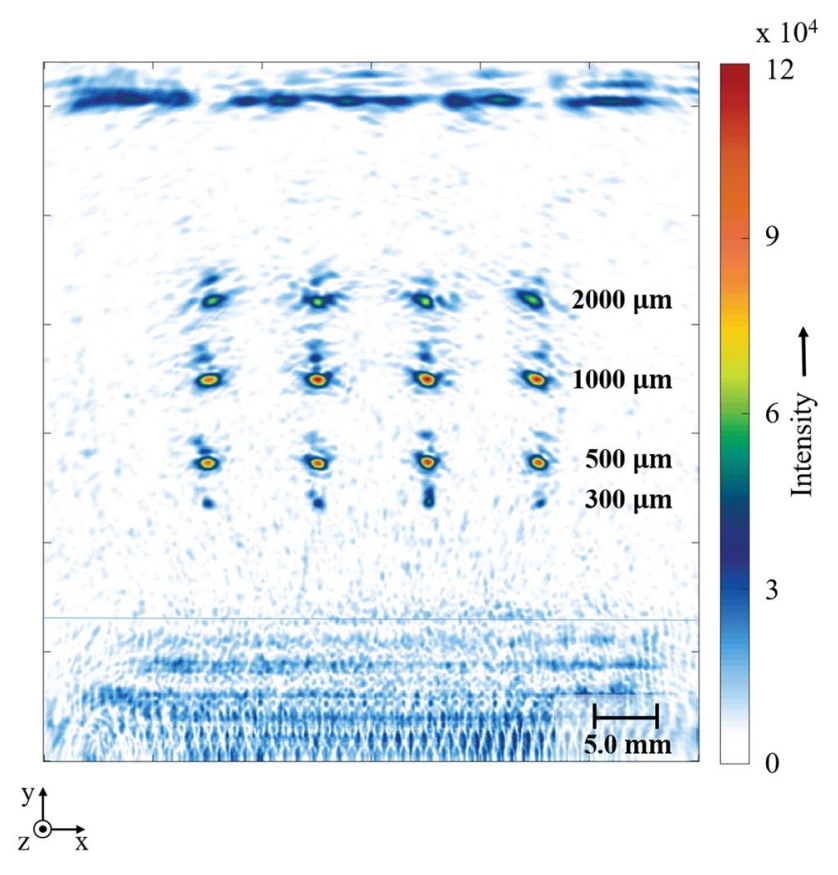

Fig. 9 TFM reconstruction result

\subsection{Metallography}

The analysis of the microsections in the SEM images revealed that only the defects of the first three rows with an intended diameter of $2000 \mu \mathrm{m}, 1000 \mu \mathrm{m}$, and $500 \mu \mathrm{m}$ could be clearly identified (see Fig. 10). Significant powder deposits on the inner walls of the channels are recognizable in the SEM images. The smaller 


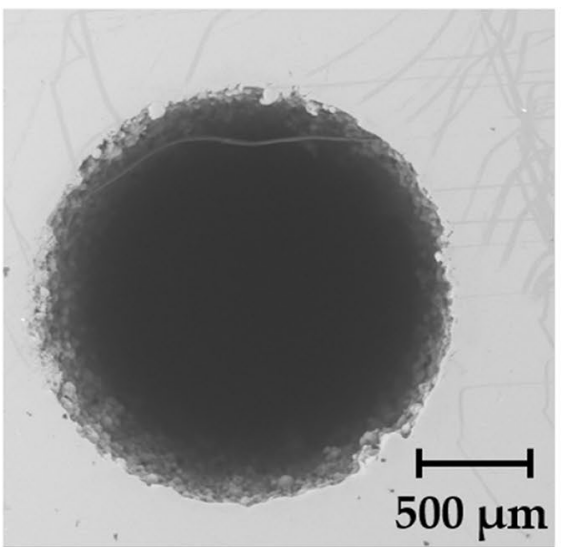

(a)

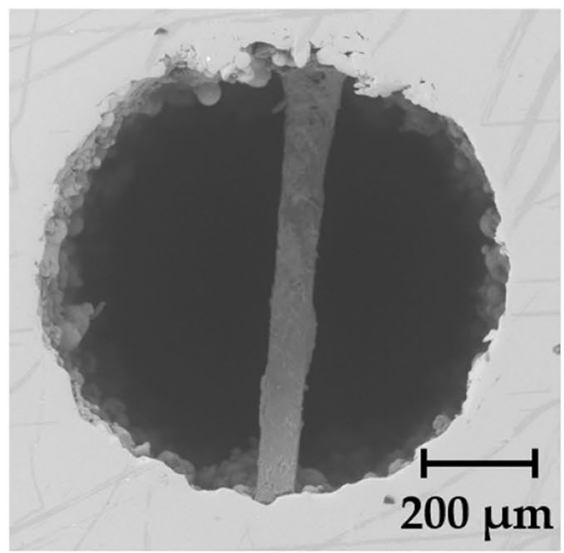

(b)

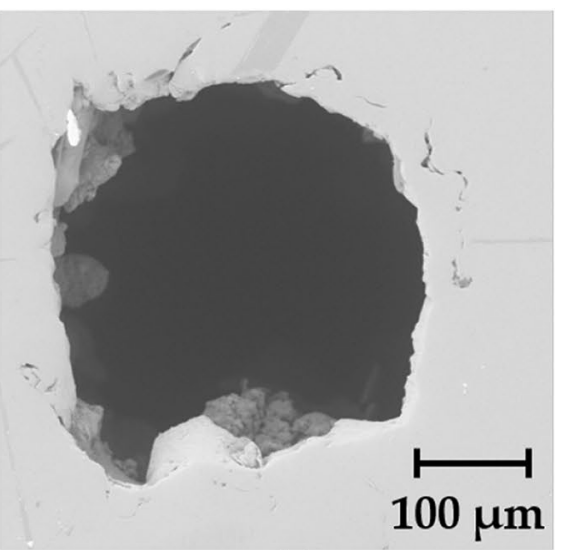

(c)

Fig. 10 SEM images of a representative defect in the row of the defects with an intended diameter of a $2000 \mu \mathrm{m}, \mathbf{b} 1000 \mu \mathrm{m}$, and c $500 \mu \mathrm{m}$ (acceleration voltage: $15 \mathrm{kV}$, signal type: mixed modus)

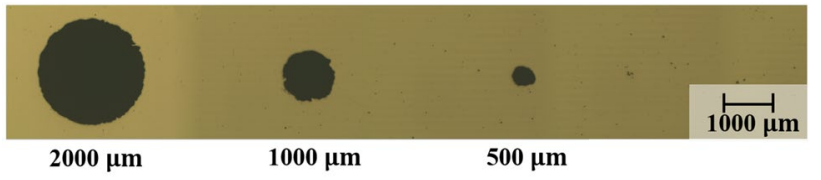

Fig. 11 Optical microscope images of a representative row of defects; the defects with an intended diameter of $2000 \mu \mathrm{m}$, $1000 \mu \mathrm{m}$, and $500 \mu \mathrm{m}$ are clearly discernible

the diameter of the defect, the greater seems to be the influence of the powder accumulations on the dimensional accuracy of the defect geometry. For the defect with an intended diameter of $1000 \mu \mathrm{m}$, even a solidified connection between opposite points of the inside of the wall is discernible (see Fig. 10b). The findings within SEM are consistent with the results of the optical microscope, whereby no definite conclusions can be drawn regarding the geometry of the defects. Due to the manual preparation of the respective cutting planes of the test specimen as well as the evaluation process, random pores could barely be distinguished from artificial defects with decreasing diameter. Defects with a diameter of less than $500 \mu \mathrm{m}$ could not be detected with sufficient certainty by microscopic imaging. However, delaminations and cracks can be in the order of magnitude of a few $100 \mu \mathrm{m}$. These defect types predominantly lead to component failure, while pores, especially small pores, usually cause rather minor weakening of the mechanical component properties $[49,50]$. If these are present in large numbers, they can also negatively affect the mechanical properties [51]. Furthermore, it was observed that the test specimen contains a large number of natural defects, which are in the order of magnitude of the artificial defects with a diameter of $20 \mu \mathrm{m}$ and smaller (Fig. 11).

\section{Discussion}

The characteristics of the defect detectability and specification depend strongly on the NDT methods, sensors, and devices used. The results of this study are discussed individually for the NDT methods in the following:

alRTThe results from the alRT displayed the lowest resolution. The open artificial defects were detected up to a defect size of $300 \mu \mathrm{m}$. The closed artificial defects were not identified. It is possible that with a different excitation, for example, ultrasonic or inductive excitation, these defects could be detected. Nevertheless, the findings showed that alRT is suitable for investigating surface inhomogeneities, such as the melting tracks and exposed defects. With the aim of improving the resolution achieved with aIRT in further studies, the suitability of different excitation sources, such as flash excitation, must be investigated further. An essential advantage of alRT is that it enables contactless component inspections. The test surface, however, must be accessible for the sensor system, which can be challenging for AM components that are often geometrically complex. Besides, a non-uniform heat input or environmental disturbances can also negatively affect the measurement results. The decrease in sensitivity with an increasing inspection depth limits ex situ aIRT applications. Layerwise monitoring of the L-PBF process in the infrared spectrum, however, allows small flaws close to the build surface, such as a lack of fusion [52], to be detected.

$X$-ray $C T$ The volumetric analysis of the test specimen provides precise information on the defect specification and location. The contrast in the measurement results of this study, however, was comparably low, which was mainly caused by scattered radiation and the high X-ray attenuation of the material. This prevented the features introduced that were less than or equal to $300 \mu \mathrm{m}$ from 
being detected reliably. In addition, due to the high density of the material, a high tube voltage and current were used to achieve sufficient contrast. However, this leads to a larger spot and thus to a poorer resolution. It should be noted that this low resolution is also a consequence of the rather large sample and the resulting low magnification. More modern X-ray systems, such as the Xradia 620 Versa from Zeiss, could still achieve high resolution in this case by using optical magnification in addition to geometric magnification. Another factor limiting the detectability of the defects is entrapped powder in the artificial defects. If the resolution is not sufficient to distinguish the powder particles from the bulk material, defects cannot be detected. In Obaton et al. [34], a similar specimen with artificial defects was investigated using X-ray CT with a synchrotron X-ray source. The voxel size achieved was $23.3 \mu \mathrm{m}$. With this setup, defects as small as $150 \mu \mathrm{m}$ were detected, which is the smallest size of the artificial defect in the sample. The higher resolution compared to the setup in this paper results from the different $C T$ setup.

The geometric complexity of AM components is not as critical for the applicability of CT as it is for other volume inspection methods, like ultrasonic testing. Due to the contactless measurement concept, conventional CT systems do not require the development of elaborate coupling or sensor mounting concepts, for example. Nevertheless, the achievable sensitivity for irregular part geometries deteriorates with conventional circular measurement trajectories and reconstruction algorithms. This is caused mainly by scattered radiation and lack of penetration, among other factors, which worsen the overall image quality. Furthermore, scattering and attenuation are influenced by the type of material, in particular their density and atomic number. Titanium and aluminum are less dense compared to Inconel, which enables higher possible resolution capability. Despite these limitations, $\mathrm{CT}$ is a very powerful inspection technique for reliably evaluating a large number of different defect types in metallic components and is thus often the primary choice in the AM field.

$n G l$ The smallest and deepest defects were recognizable with $\mathrm{nGl}$. $\mathrm{nGl}$ can, in some cases, be considered a complementary NDT method to X-ray CT. Radiography with neutrons allows both light and heavy elements to be analyzed, since the neutron attenuation cross section does not show an ordered dependence on the atomic number. In contrast, radiography with $X$-rays has a wellordered dependence of the attenuation cross section on the atomic number, with higher atomic numbers leading to a larger cross section. By extending $\mathrm{nGl}$ to $3 \mathrm{D}$ (tomography), the geometrical extension of defects can be further investigated.

UT Using the total focusing method yielded a higher resolution of the defects compared to alRT. TFM facilitates a layer-by-layer examination of the test specimen and also allows a three-dimensional reconstruction when matrix arrays are chosen. In order to further optimize the TFM result, more precise velocity data are required. In this context, an isotropic sound velocity of the longitudinal wave mode was considered in this study (i.e., the velocity perpendicular to the inspection surface). The build direction of additively manufactured parts can, however, affect the elastic properties and thus the speed of sound (see Tofeldt et al. [53]). By incorporating anisotropic velocity data into the TFM algorithm, imprecise or unwanted phase summations can be avoided, improving the sensitivity to smaller defects [48]. In the presented study, defects with a diameter larger than $300 \mu$ m could be identified. A comparable study is given in Obaton et al. [34]. In this, defects as small as $100 \mu \mathrm{m}$ were visualized with TFM. The higher resolution compared to our study may be due to the different material, which was investigated. The specimen in Obaton et al. [34] was manufactured from aluminum, which is less anisotropic than Inconel 718. Furthermore, Inconel 718 scatters the elastic waves more strongly, which leads to higher noise levels. In general, ultrasonic testing can be challenging when inspecting rough materials that are irregular in shape. A robust coupling concept including an automated inspection is required to process detailed images from the recorded raw data.

Metallurgical testing The analysis of the microsections showed that it is hard to distinguish smaller defects clearly from random inhomogeneities, such as pores. Therefore, it is challenging to evaluate which defects were present in the test specimen investigated. It is expected that small defects would be closed during the manufacturing process, since the diameter of the smallest artificial defects is in the order of magnitude of the diameter of few powder particles. Unconsolidated powder particles can be attracted by the melt pool, leading to a partial closure of the channels. Also, the preparation steps, such as grinding and polishing, can lead to the closure of the defects on the prepared surface.

It is fair to state that the attainable resolution for all examined NDT methods depends significantly on the dimensions of the test specimen. For the specimens tested in this study, the minimum detected defect sizes are given in Table 6. The best resolution was achieved with $\mathrm{nGl}$. Defects with a minimum detected defect diameter of 100 $\mu \mathrm{m}$ could be recognized. This demonstrates that artificial defects of this size can be produced through the L-PBF process. However, the results do not allow any conclusions to be drawn regarding the minor defects. It is not possible to determine whether smaller defects were not detected by the NDT methods or were not present in the test specimen. The latter is caused by instabilities in the generation of the respective melting tracks. Powder in the cavities can 
Table 6 Overview of the examined NDT methods with the respective minimum detected defect size

\begin{tabular}{ll}
\hline NDT method & $\begin{array}{l}\text { Minimum } \\
\text { detected } \\
\text { defect size }\end{array}$ \\
\hline Active infrared thermography (open defect) & $300 \mu$ \\
Active thermography (closed defect) & $\times$ \\
X-ray computed tomography & $300 \mu$ \\
Neutron grating interferometry (DFI) & $200 \mu$ \\
Neutron grating interferometry (TI) & $100 \mu$ \\
Ultrasonic testing & $300 \mu$ \\
\hline
\end{tabular}

then be thermally activated by the melting bath via heat conduction [54]. This leads to a melting and remelting of the unsolidified powder contained in the cavities and thus to a closing of the artificial defects.

Furthermore, based on the findings of this study and the experience of the respective research groups, the NDT methods were assessed with regard to their properties in Table 7. The assumptions in Table 7 were made on the basis of the results of this article, literature research, and the experience of the respective research groups involved in the article. This table is intended to give the reader only a first impression of the main properties of the individual NDT methods for testing additive manufactured materials. The respective properties always depend on the specific inspection task and the available resources and may therefore also differ from this table.

\section{Conclusions}

This paper presents a first comparison of a selection of NDT methods with respect to their defect detection capability in L-PBF parts made from Inconel 718. The investigated methods included active infrared thermography (alRT), X-ray computed tomography (CT), neutron grating interferometry ( $\mathrm{nGl})$, and ultrasonic testing (UT). For reasons of reproducibility, the experiments were performed with the same test specimen containing artificial defects with varying diameters and depths in an ex situ setup. The findings of this paper can be summarized as follows:

- The best resolution was achieved with nGl. However, this is also the most time-consuming and expensive method.

- An alternative to $\mathrm{nGl}$ for detecting defects in a volume is X-ray CT. For small samples, $\mathrm{X}$-ray CT offers good resolution in the $m$ range. As the sample size increases or the material becomes denser, the resolution becomes much poorer until the $\mathrm{X}$-rays are no longer transmitted through the part. In this case, UT could be advantageous.

- alRT offers a fast and easy analysis of near-surface defects. However, the resolution and especially the penetration depth are worse compared to the other NDT methods. Subsurface defects could not be detected in this study, which limits the application of this method.

Consequently, the findings corroborate that the use of different NDT methods can compensate for the disadvantages of the methods. For example, $\mathrm{X}$-ray CT could be used to validate UT in small parts to examine larger parts with UT.

Investigating the method-dependent Probability of Detection remains a crucial effort in the future. This requires a significantly larger scope and test specimens with a wide distribution of defect sizes. Since particularly small defects cannot be artificially produced, naturally occurring defects are required for this study. These process-related defects can be caused by process instabilities due to an unfavorable variation of the process parameters. In addition, the analysis of the maximum defect resolution as a function of the dimensions and geometric complexity of the test specimen and its material is an important aspect for further investigations. Another influence that is of interest for the detection of defects is their morphology and thus the type of defect. 


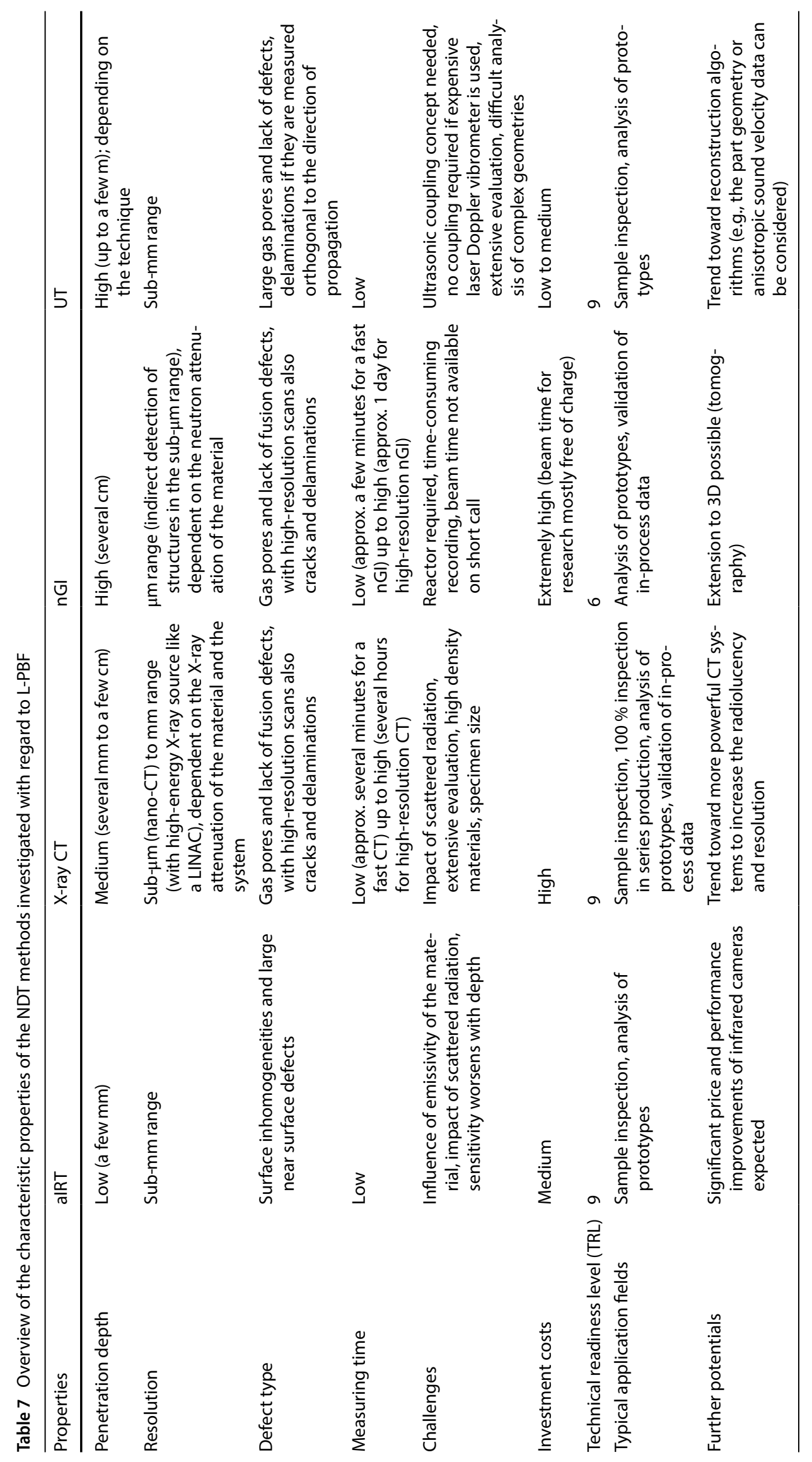


Funding Open Access funding enabled and organized by Projekt DEAL. This research did not receive any specific grant from funding agencies in the public, commercial, or non-for-profit sector. The experiments investigating the capability of neutrons for the defect detection were conducted at the ANTARES instrument operated by FRM II of the Heinz Maier-Leibnitz Zentrum (MLZ), Garching, Germany. Furthermore, this work was supported by FIT AG, Lupburg, Germany, who provided CT scans. The authors would like to thank Brigitte Hadler from the Institute for Machine Tools and Industrial Management of the Technical University of Munich. The contributions of all institutions to this work are gratefully acknowledged.

Data availability The raw/processed data required to reproduce these findings cannot be shared at this time due to technical or time limitations.

\section{Declarations}

Conflict of interest The authors have no conflicts of interest.

Open Access This article is licensed under a Creative Commons Attribution 4.0 International License, which permits use, sharing, adaptation, distribution and reproduction in any medium or format, as long as you give appropriate credit to the original author(s) and the source, provide a link to the Creative Commons licence, and indicate if changes were made. The images or other third party material in this article are included in the article's Creative Commons licence, unless indicated otherwise in a credit line to the material. If material is not included in the article's Creative Commons licence and your intended use is not permitted by statutory regulation or exceeds the permitted use, you will need to obtain permission directly from the copyright holder. To view a copy of this licence, visit http://creativecommons. org/licenses/by/4.0/.

\section{References}

1. Yap CY, Chua CK, Dong ZL, Liu ZH, Zhang DQ, Loh LE, Sing SL (2015) Review of selective laser melting: materials and applications. Appl Phys Rev 2:041101. https://doi.org/10.1063/1.49359 26

2. Elmer J, Allen S, Eager T (1989) Microstructural development during solidification of stainless steel alloys. Metall Trans 20:2117-2131. https://doi.org/10.1007/BF02650298

3. Buchbinder $D$, Schleifenbaum $H$, Heidrich $S$, Meiners W, Bültmann J (2011) High power selective laser melting (HP SLM) of aluminum parts. Phys Proc 12:271-278. https://doi.org/10. 1016/j.phpro.2011.03.035

4. Everton S, Hirsch M, Stravroulakis P, Leach R, Clare A (2016) Review of in-situ process monitoring and in-situ metrology for metal additive manufacturing. Mater Des 95(5):431-445. https:// doi.org/10.1016/j.matdes.2016.01.099

5. Rehme O, Emmelmann C (2005) Reproducibility for properties of selective laser melting products. In: Lasersin manufacturing 2005: proceedings of the third international WLT conference lasers in manufacturing, LIM 2005, Munich, Germany, June 13th-16th, 2005. AT-Fachverl, Stuttgart. ISBN: 978-3-00-0164026. https://www.tib.eu/de/suchen/id/BLCP\%3ACN068599180/ Reproducibility-for-properties-of-selective-laser/

6. Palm M, Chandelle A, Riß F, Zäh M (2019) Overview and classification of defects occurring during laser beammelting of nickelbased alloys. In: Production at the leading edge of technology, pp 379-388. https://doi.org/10.1007/978-3-662-60417-5_38
7. Palm M, Chandelle A, Riß F, Zäh M (2019) Overview and classification of defects occurring during laser beam melting of nickelbased alloys. In: Production at the leading edge of technology, pp 379-388. https://doi.org/10.1007/978-3-662-60417-5_38. https:// link.springer.com/chapter/10.1007/978-3-662-60417-5_38

8. Hauser C, Childs THC, Dalgarno KW, Eane RB (1999) Atmospheric control during direct selective laser sintering of stainless steel 3145 powder. In: 10th international solid freeform fabrication symposium, Austin (Texas). https://doi.org/10.26153/tsw/747

9. Gong H, Rafi K, Gu H, Starr T, Stucker B (2014) Analysis of defect generation in Ti-6Al-4V parts made using powder bed fusion additive manufacturing processes. Addit Manuf 1:87-98. https:// doi.org/10.1016/j.addma.2014.08.002

10. Vilaro T, Colin C, Bartout JD (2011) As-fabricated and heattreated microstructures of the Ti-6Al-4V alloy processed by selective laser melting. Metall Mater Trans A 42:3190-3199. https://doi.org/10.1007/s11661-011-0731-y

11. Ladewig A, Schlick G, Fisser M, Schulze V, Glatzel U (2016) Influence of the shielding gas flow on the removal of process byproducts in the selective laser melting process. Addit Manuf 10:1-9. https://doi.org/10.1016/j.addma.2016.01.004

12. Gu D, Hagedorn YC, Meiners W, Meng G, Batista RJS, Wissenbach K, Poprawe R (2012) Densification behavior, microstructure evolution, and wear performance of selective laser melting processed commercially pure titanium. Acta Mater 60:3849-3860. https://doi.org/10.1016/j.actamat.2012.04.006

13. Carter LN, Wang X, Read N, Khan R, Aristizabal M, Essa K, Attallah MM (2016) Process optimisation of selective laser melting using energy density model for nickel based superalloys. Mater Sci Technol 32:657-661. https://doi.org/10.1179/1743284715Y. 0000000108

14. Kolb C, Bayerlein F, Zaeh M (2017) Active thermography as a process monitoring technology for laser beam melting: an ex-situ and in-situ feasibility study. In: Proceedings of the 16th rapid tech conference Erfurt, Germany, 05-07 June 2017. ISBN: 9783-446-45811-6. https://www.hanser-elibrary.com/doi/abs/10. 3139/9783446458123.012

15. Runnemalm A, Broberg P, Fernandez E, De LA Yedra A, Henrikson $\mathrm{P}$, Thorpe $\mathrm{N}$ (2014) Automatic thermography inspection of welded components with limited access. In: 6th international symposium on NDT in aerospace, 12-14 November, Madrid, Spain, pp 1-10. https://www.ndt.net/events/aeroNDT2014/ app/content/Paper/7_Runnemalm_Rev2.pdf

16. Fedala Y, Streza M, Sepulveda F, Roger J, Tessier G, Boué C (2014) Infrared lock-in thermography crack localization on metallic surfaces for industrial diagnosis. J Nondestr Eval 33(3):335-341. https://doi.org/10.1007/s10921-013-0218-4

17. Shepard S, Hou J, Lhota J, Golden J (2007) Automated processing of thermographic derivatives for quality assurance. Opt Eng 46(5):051008. https://doi.org/10.1117/1.2741274

18. Merkle P, Cates J, Correa E, Bartberger J, Trujillo M (2010) Active thermal standoff inspection for physical authentication. Sandia National Laboratories. https://media.nti.org/pdfs/SNL-3_FINAL_ INMM_2010_Thermal_Inspection_Paper.pdf

19. Maldague $X(2002)$ Introduction to NDT by active infrared thermography. Mater Eval 60(9):1060-1073

20. Maldague $X$ (2001) Theory and practice of infrared technology for non destructive testing. Wiley, New York

21. Du Plessis A, Yadroitsev I, Yadroitsava I, Le Roux S (2018) X-ray microcomputed tomography in additive manufacturing: a review of the current technology and applications. 3D Print Addit Manuf. https://doi.org/10.1089/3dp.2018.0060

22. Lopez E, Felgueiras T, Grunert C, Brückner F, Riede M, Seidel A, Marquardt A, Leyens C, Beyer E (2018) Evaluation of 3D-printed parts by means of high-performance computer tomography. $J$ Laser Appl 30(3):032307. https://doi.org/10.2351/1.5040644 
23. Tammas-Williams S, Zhao H, Léonard F, Derguti F, Todd I, Prangnell $P$ (2015) XCT analysis of the influence of melt strategies on defect population in Ti-6Al-4Vcomponents manufactured by selective electron beam melting. Mater Charact 102:47-61. https://doi.org/10.1016/j.matchar.2015.02.008

24. Brooks A, Ge J, Kirka M, Bilheux H, Kardjilov N, Manke I, Butler $\mathrm{L}$ (2017) Porosity detection in electron beam-melted Ti-6Al-4V using high-resolution neutron imaging and grating-based interferometry. Prog Addit Manuf 2(3):125-132. https://doi.org/10. 1007/s40964-017-0025-z

25. Michaloudaki M, Lehmann E, Kosteas D (2005) Neutron imaging as a tool for the non-destructive evaluation of adhesive joints in aluminium. Int J Adhes Adhes 25(3):257-267. https://doi.org/10. 1016/j.ndteint.2017.06.004

26. Griesche A, Dabah E, Kannengiesser T, Kardjilov N, Hilger A, Manke I (2014) Three-dimensional imaging of hydrogen blister in iron with neutron tomography. Acta Mater 78:14-22. https:// doi.org/10.1016/j.actamat.2014.06.034

27. Everton S, Dickens P, Tuck C, Dutton B (2015) Evaluation of laser ultrasonic testing for inspection of metal additive manufacturing. In: Laser 3D manufacturing, vol 9353. International Society for Optics and Photonics, 935316. https://doi.org/10.1117/12. 2078768

28. Rieder H, Dillhöfer A, Spies M, Bamberg J, Hess T. Online monitoring of additive manufacturing processes using ultrasound. In: 11th European conference on non-destructive testing (ECNDT), Prague, Czech Republic. https://doi.org/10.1063/1.4914609

29. Rieder H, Dillhöfer A, Spies M, Bamberg J, Hess T (2015) Ultrasonic online monitoring of additive manufacturing processes based on selective laser melting. AIP Conf Proc 1650:184-191. https://doi.org/10.1063/1.4914609

30. Karthik N, Gu H, Pal D, Starr T, Stucker B. High frequency ultrasonic non destructive evaluation of additively manufactured components. In: 24th international solid freeform fabrication symposium, Austin (Texas), USA, pp 11-325. https://doi.org/10. $1063 / 1.4914608$

31. Klein M, Sears J (2004) Laser ultrasonic inspection of laser cladded 316LSS and Ti-6-4. In: International congress on applications of lasers \& electro-optics 2004, vol 1, p 1006. https://doi. org/10.2351/1.5060183

32. Santospirito S Topatka R, Cerniglia D, Styk K, Luo B, Panggabean D, Rudlin J (2013) Defect detection in laser powder deposition components by laser thermography and laser ultrasonic inspections. In: Frontiers in ultrafast optics: biomedical, scientific and industrial applications XIII, vol 8611, p $86111 \mathrm{~N}$. https://doi.org/ 10.1117/12.2006361

33. Cerniglia D, Scafidi M, Pantano A, Łopatka R (2013) Laser ultrasonic technique for laser powder deposition inspection. Laser 150(6):13

34. Obaton A, Butch B, McDonough S, Carcreff E, Laroche N, Gaillard Y, Tarr J, Bouvet P,Cruz R, Donmez A (2020) Evaluation of nondestructive volumetric testing methods for additively manufactured parts. In: Structural integrity of additive manufactured parts, pp 51-95. https://doi.org/10.1520/STP16202018009

35. Institut Deutsches, für Normung e.V. (2002) Technical drawings-general principles of presentation. Beuth Verlag $\mathrm{GmbH}$, Beuth

36. Zoecke C (2009) Quantitative analysis of defects in composite material by means of optical lockin thermography. Ph.D. thesis. https://doi.org/10.22028/D291-22648

37. Goldammer M, Heinrich W (2006) Active thermography for dimensional measurements on gas turbine components. In: Proceedings of 9th European conference of non-destructive testing (ECNDT), September 25-29, Berlin, Germany. ISBN: 3931381862. https://www.ndt.net/article/ecndt2006/doc/Tu.3.8.1.pdf
38. Pfeiffer F, Gruenzweig C, Bunk O, Frei G, Lehmann E, David C (2006) Neutron phase imaging and tomography. Phys Rev Lett 96(21):215505. https://doi.org/10.1103/PhysRevLett.96.215505

39. Pfeiffer $F$, Bech $M$, Bunk $O$, Kraft $P$, Eikenberry $E$, Broennimann C, Gruenzweig C, David C (2008) Hard-X-ray dark-field imaging using a grating interferometer. Nat Mater 7(2):134. https://doi. org/10.1038/nmat2096

40. Gruenzweig C, David C, Bunk O, Dierolf M, Frei G, Kuehne G, Schaefer R, Pofahl S, Rønnow H, Pfeiffer F (2008) Bulk magnetic domain structures visualized by neutron dark-field imaging. Appl Phys Lett 93(11):112504. https://doi.org/10.1063/1.29758 48

41. Anderson I, McGreevy R, Hassina Z (2009) Neutron imaging and applications: a reference for the imaging community. Technical report, ISBN 978-0-387-78692-6. https://link.springer.com/book/ 10.1007\%2F978-0-387-78693-3

42. Strobl M (2014) General solution for quantitative dark-field contrast imaging with grating interferometers. Sci Rep 4:7243. https://doi.org/10.1038/srep07243

43. Reimann $T$, Muehlbauer $S$, Horisberger $M$, Betz B, Boeni $P$, Schulz M (2016) The new neutron grating interferometer at the ANTARES beamline: design, principles and applications. J Appl Crystallogr 49(5):1488-1500. https://doi.org/10.1107/S1600 576716011080

44. Schulz M, Schillinger B (2015) Cold neutron radiography and tomography facility. J Large-Scale Res Facil 1:17. https://doi.org/ 10.17815/jlsrf-1-42

45. Calzada E, Gruenauer F, Muehlbauer M, Schillinger B, Schulz M (2009) New design for the ANTARES-II facility for neutron imaging at FRM II. Nucl Instrum Methods Phys Res Sect A Accel Spectrom Detect Assoc Equip 605(1-2):50-53. https://doi.org/ 10.1016/j.nima.2009.01.192

46. Holmes C, Drinkwater B, Wilcox P (2005) Post-processing of the full matrix of ultrasonic transmit-receive array data for nondestructive evaluation. NDT E Int 38(8):701-711. https://doi. org/10.1016/j.ndteint.2005.04.002

47. Dube N (2007) Introduction to phased array ultrasonic technology applications: R/D guideline, advanced practical NDT series, Olympus NDT,

48. Grager J, Mooshofer H, Grosse C (2018) Evaluation of the imaging performance of a CFRP-adapted TFM algorithm. In: ECNDT proceedings of 12th European conference on non-destructive testing (ECNDT), June 11-15, 2018, Gothenburg, Sweden. ISBN: 978-91-639-6217-2. https://www.ndt.net/search/docs.php3?id= 22766

49. Romano S, Brandão A, Gumpinger J, Gschweitl M, Beretta S (2017) Qualification of AM parts: extreme value statistics applied to tomographic measurements. Mater Des 131:32-48. https:// doi.org/10.1016/j.matdes.2017.05.091

50. Reschetnik W, Brueggemann JP, Aydinoez ME, Grydin O, Hoyer KP, Kullmer G, Richard HA (2016) Fatigue crack growth behavior and mechanical properties of additively processed EN AW-7075 aluminium alloy. Proc Struct Integr 2:3040-3048. https://doi. org/10.1016/j.prostr.2016.06.380

51. Rice RW (1997) Limitations of pore-stress concentrations on the mechanical properties of porous materials. J Mater Sci. https:// doi.org/10.1023/A:1018674713006

52. Goegelein A, Ladewig A, Zenzinger G, Bamberg J (2018) Process monitoring of additive manufacturing by using optical tomography. In: DGZfP proceedings BB 167 of 14th quantitative infrared thermography conference, June 25-29, 2018, Berlin, Germany. ISBN: 978-3-940283-94-8004. https://doi.org/10.1063/1. 4914606

53. Tofeldt O, Pierce S, Smillie G, Kerr W, Flockhart G, Macleod C, Blue R, Gachagan A, Stratoudaki T, Olsson J, McMahon D (2018) Investigation of fundamental ultrasonic propagation characteristics 
in NDT of electron beam melted additive manufactured samples-Inconel 718. In: ECNDT proceedings of 12th European conference on non-destructive testing (ECNDT), June 11-15, 2018, Gothenburg, Sweden. ISBN: 978-91-639-6217-2. https:// strathprints.strath.ac.uk/63751/
54. Gusarov AV, Smurov I (2010) Modeling the interaction of laser radiation with powder bed at selective laser melting. Phys Proc 5:381-394. https://doi.org/10.1016/j.phpro.2010.08.065

Publisher's Note Springer Nature remains neutral with regard to jurisdictional claims in published maps and institutional affiliations. 